\title{
Analysis on New Carrier of Ideological and Political Education for College Students
}

\author{
Jing $\mathrm{XiaO}^{1, \text { a }}$ \\ ${ }^{1}$ Xi'an Aeronautical University, Xi'an, ShanXi, China, 710077 \\ ${ }^{a}$ email,
}

Keywords: New Carrier, Ideological and Political Education, College Students

\begin{abstract}
Ideological and Political Education in the New Carrier of University Students Ideological and Political Education is an intermediary platform, is a new form of the carrier under the science and technology development and productivity and improve the situation of the formation, which is the material basis and guarantee of ideological and political education activities. Ideological and political support to carry out research education, in widening the ideological and political education, ideological and political support in the form of a rich education, ideological and political education resources integration, improve the effectiveness of ideological and political education has important practical significance.
\end{abstract}

\section{Introduction}

Strengthening and improving ideological and political education is an important and urgent strategic task. Currently, some college students in the face of complex relationships, changing social environment, fierce academic competition, lack of confidence when the severe employment situation, poor adaptability. These phenomena are not only objective, but also very common. In preaching "indoctrination" as the main ideological education model has been unable to fully meet the needs of the students thought. To this end, explore effective ways and means of ideological and political education has been placed in front of many educators a critical issue.

With the rapid development of information technology, networking social, ideological and political education to rely solely on the traditional model cannot meet the needs of the times. Full use of various effective carrier is to carry out ideological and political education is the inevitable trend of ideological and political education. Diversification carrier new media, Internet and other ideological and political education has brought new opportunities and presents new challenges. The use of various forms of support to carry out ideological and political education is an urgent need for the development of the era of ideological and political education proposed in the new era is to carry out a full range of practical needs ideological and political education. However, due to the diversification carrier construction has certain shortcomings, therefore, how effective ideological and political education innovation carrier construction, ideological and political education workers have yet to be studied. Currently, many new media have become the contemporary Chinese college students understand the world of the most important tools and approaches, and their ideas have a broad and profound impact. Ideological and Political Educators should fully understand and grasp the carrier construction of ideological and political education to bring favorable opportunities, develop ideas, and strive to explore new ways and methods to carry out ideological and political work under the new situation, in order to improve the ideological and political education effectiveness.

Due to the influence of social environment, ideological and political education is facing tremendous pressure, especially how to combine social actual ideological and political education, how to lead the society rather than being led society, it also faces enormous challenges. In short, the moment relies solely on indoctrination and education has been feasible, or far less than ideal results. Network era, era of pictures, we must combine the characteristics and psychological needs of the times to do ideological and political education of college students. Undoubtedly, the new good carrier is more able to attract college students to enable them to upgrade themselves in the 
entertainment, self-improvement and a new way to effectively enhance the ideological and political education of college students. If we do not take the initiative to occupy the market, take advantage of non-mainstream thinking will greatly interfere with College Students and Their Education. In fact, the current ideological and political education of college students cannot meet the spiritual and cultural needs, it is necessary to work to strengthen work in this area. Eventually forming a good situation leading colleges and universities, teachers and students actively participate. Schools, groups, individuals together to force the political education carrier construction will often start new, and carrier performance played but will only lasting impact was more extensive and far-reaching, according to the party's request to continue the ideological and political educational work onto a new level of development.

\section{The New Carrier of Ideological and Political Education for College Students}

The Network Communication Carrier. Weblog is the English abbreviation, Chinese translation for "Web log." It is the first use of blog in the last century and it was born in the United States. 2002 will be introduced into China blog. Today it has already become well-known Chinese Internet users communication tools, and created the "micro-blogging" and other more efficient and flexible forms. Blog of their own media made it an ideological and political education carrier feasible. One is simplicity. From a blog account, and then to publish the blog post was "concerned" that the whole process simple and easy to operate, does not require much expertise and editing skills. The second is interactive. Bloggers can mutual "concern" on the Internet to complete the exchange of ideas and influenced each row into a new outlook on life and values. Blog quickly will pass the information to be expressed in relatively out and will soon be able to respond to the object, to convey the effect also can receive timely feedback. College students are the main force of Internet use, their learning, life and networks are closely related. They use the network to learn the ways and means, the use of friends, entertainment, networking is also becoming more common.

Bulletin Board System is the English acronym, literally "electronic bulletin board system," which is an electronic information service system on the Internet, which provides a public electronic communication platform and each user can write on, publish information or express their views. Forum BBS access rate to $38.8 \%$ of the proportion among the top ten web applications, wherein users 30 years of age accounted for $68.6 \%$ of Chinese Internet users. Under the new situation, the rapid development of Internet, the university BBS become the new carrier has been ideological and political education is an inevitable trend. University BBS for the students and faculty provided a broad space for the exchange, it is a free and open internet. By registering certification program after landing you can anonymously post their views on the BBS, the exchange of personal interests, hobbies.

QQ group is an additional service and a certain number of QQ users to gather long-term stability of the public chat rooms, group members can exchange information with each other through voice, text, video and other means. QQ group of college students is a familiar, loved by the exchange platform. In the QQ group, two-way communication mode of thinking will be well represented, no serious hierarchy, interpersonal pressure will be significantly smaller. QQ all group members can either take a group chat mode, you can also choose whisper way to communicate. Ideological and political workers will be able to timely comments made by college students, to answer the questions. Group chat between students will inadvertently reveal many psychological dynamics of small details, the ideological and political education workers will be able to carry out targeted work.

Electronic Media Carrier. IPTV is an interactive network TV, is a use of broadband cable networks, set in a variety of Internet technology, multimedia, communications and other; including digital television, including a variety of interactive services to home users of new technologies. Users at home can enjoy IPTV services in two ways: (1) computer, (2) normal TV + network set-top boxes. Media from a single to a comprehensive and humane development is a fundamental rule, interactive TV it is a good interpretation of this law. Currently, interactive TV has begun to take shape in China and it is changing the functions of the traditional television, and gradually reflects the interaction. 
Electronic database is followed by the development and widespread application of computer technology generated. It is certain data stored in the computer can be set according to the data by integrating user needs to be used. Electronic database collection of graphic information society is in various fields, as well as video, audio and other multimedia data. Electronic databases content very convenience. Because its contents are arranged in a certain order and the use of computer software and data-one link that allows users to quickly find the data they need in the screening process. Colleges electronic database rich information resources are a strong complement to the school library resources.

SMS Support. Other features need the help of SMS message sender and receiver to interact reflected. In the mobile phone short message sending and feedback process, the sender or the recipient of the information is only relative, so that the traditional SMS Speech Communication recipient has become an object of interest. SMS interactivity is implemented in the interaction process. SMS sender must consider in advance how the rhetoric, what kind of expression, the other more acceptable, this process is called SMS design. In the meantime, the recipient is also receiving SMS Consideration way. SMS is different from traditional media newspapers, radio, television and other features is its confidentiality. SMS is a sender and a receiver intimate communication, information dissemination is a kind of confidential nature. Chats traditional media or paper files are likely to be rendered inadvertently leaked, and SMS whenever a user not to disclose information content can always delete operation, no way to spy on others. Using SMS privacy features.

Student Community Support. Community colleges and universities, including student organizations: Student party organizations, student organizations, volunteer service organizations. Students community organizations have democracy and self-management of the students are participants in these organizations with practitioners, so that students of management ability, self-learning ability and interpersonal communication skills to get an excellent workout. Students 'caucus organization is an extension of school organization, and take self-education students' political and ideological functions effectively promote the comprehensive development of students. Community party organizations are the core of other community activities; student associations enrich the campus culture and strengthening the college students' sense of participation and responsibility. Students 'Community Management student is an autonomous organization of students' daily work, is the subject of community management; college students volunteer service organization is a responsible, professional skills and expertise of the group, they are community cultural activities, routine, self-education and other activities of the backbone.

\section{The Construction Way of Ideological and Political Education New Carrier}

Establish Scientific Campus Network Management System. The establishment of a network management system is the key person, has been established professional, excellent professional network management team is particularly important. School-related departments, mainly school students and staff working at the branch to assume supervision of the student website. Of course, college students has a very proactive network utilization groups, school students should also explore among horizontal, technology backbone of molecules involved in the construction of the campus network management ranks, such self-management and self-education so that students are more willing to accept school network management. Specialized teams need to have plans in-depth training targeted network-related knowledge, so that the ideological and political education workers on the basis of understanding and use of the network learned on the further use of network technology into the more ideological and political education to which network and deepen the ideological and political education and networking support links and integrate use. To improve the quality of information to grasp and handle aspects, able to skillfully use the network, controlling the network, and solve the problems in network communication, efforts to make ideological and political education vivid, with a strong attraction and appeal.

Strengthen Regulatory Oversight Campus Network Content. College Network content regulation is to establish a foothold guidance, coordination and feedback mechanisms of sound public opinion, and the degree of attention the current campus network content regulation is not 
enough for students to network intensification of conflicts, harmful information filtering to timely regulation and proper disposal, resulting in a network management loopholes, to sex, crime and other unhealthy information swoop, web content to campus green, stable development caused a bad influence. Ideological and political workers should be based on supporting the country's Internet regulations effectively enhance students' network content supervision, to provide protection for the college formed a healthy network environment.

The Existing Carriers Continue To Add New Educational Content. Political and Ideological Education in the form of increasingly diverse, social, ideological and political education so that existing load carriers more information, spread more convenient, plus easy operation. It should be targeted on the integration and optimization of existing carrier, purposeful increases the existing carriers in the form and content of ideological and political education to maximize the effectiveness of existing carrier. So as to form a good academic atmosphere in universities, we should build a harmonious campus environment. Existing ideological and political education carriers often do not combine the existing scientific and technological achievements and information technology is not high, limited transmission range. The current gradual rise new media is not only to achieve a carrier to limit global network coverage, but also regardless of time of great convenience. Existing ideological and political education can join the carrier of modern technology, the rich scientific and cultural knowledge and a lot of political and ideological factors implicit manner through information dissemination. Students learn socialist ideology and moral theory, it was always boring, boring and educators can be through the construction of "Red" website to enhance college students' patriotism, enhance their understanding of the Communist Party of China's revolutionary history and tradition of excellence.

\section{Conclusion}

New Carrier of ideological and political education is a realistic and age of the subject. Since China's entry into the information society, the Internet as the representative of the carrier in the form ascendant, ideological and political education has brought fundamental change, various other new media also joined in the field, is a profound impact on college students' thinking and behavior. Ideological and political education in the new situation is facing many challenges and the traditional ideological and political education carrier in a complex social environment has lost its original effectiveness, a subtle change. Urgent need to change our thinking and ideological and political workers, with the times, and actively support the necessary innovation to adapt to the new form of vector construct modern social development and requirements of the times.

\section{References}

[1] Xu Qun. Higher Education Research and Evaluation, Vol. 6 (2004) No 53, p.25-26

[2] Wang Yunhui, Wang Qunyong. Border Economy and Culture, Vol. 12 (2005) No 27, p.74-76

[3] Jing Jianfen, Hou XuSiem. Education and Vocation, Vol. 30 (2004) No 19, p.144-145

[4] Wang Kuailiang. Higher Education Forum, Vol. 29 (2008) No 27, p.21-23

[5] Zhang Gongxu, Sun Jing. Political and Ideological Work, Vol. 8 (2003) No 27, p.57-60 